\title{
Mixed dose
}

National Diabetes Information Clearinghouse (NDIC)

\section{Definitions}

Insulin

Defined by National Diabetes Information Clearinghouse (NDIC)

Short-acting insulin

Defined by National Diabetes Information Clearinghouse (NDIC)

\section{Rapid-acting insulin}

Defined by National Diabetes Information Clearinghouse (NDIC)

Injection

Defined by National Diabetes Information Clearinghouse (NDIC)

Blood glucose level

Defined by National Diabetes Information Clearinghouse (NDIC)

\section{Source}

National Diabetes Information Clearinghouse (U.S.). (2009). The diabetes dictionary. [Bethesda, Md.]: U.S. Dept. of Health and Human Services, National Institutes of Health, National Institute of Diabetes and Digestive and Kidney Diseases, National Diabetes Information Clearinghouse.

A combination of two types of insulin in one injection. Usually a rapid-or short-acting insulin is combined with a longer-acting insulin to provide both short- and long-term control of blood glucose levels. 